\title{
SUN PROTECTOR FACTOR (SPF) IN VITRO AND THE PHYSICAL STABILITY OF O/W CREAM OPTIMAL FORMULA FROM THE PARTITION PRODUCT OF MAHKOTA DEWA LEAVES [Phaleria macrocarpa (Scheff) Boerl]
}

\author{
Abdul Karim Zulkarnain, Marchaban*, Subagus Wahyuono, \\ Ratna Asmah Susidarti
}

Faculty of Pharmacy, Universitas Gadjah Mada, Yogyakarta.

Skip Utara 55291,

Yogyakarta

Submitted: $11-06-2015$

Revised: $12-08-2015$

Accepted: 15-10-2015

*Corresponding author Marchaban

Email:

marchaban@yahoo.com

\begin{abstract}
The leaves Mahkota dewa leaves (Phaleria macrocarpa (Scheff) Boerl) contain a benzophenoic glycoside (Phalerin) which are active for sun screen. Some formula and design on the Simplex Lattice Design (SLD) method and its physical characteristics were investigated. The physical characteristics will be used to determine the optimum formula. In present study, the optimum formulation was evaluated to determine chemical stability and the in vitro SPF (Sun Protecting Factor). The doses of partition product of $P$. macrocarpa used were used $6 \%$. The optimal formulation cream was determined by SLD version 9.0.1 with variety of cetyl alcohol, mineral oil, and Tween 80 . The difference of physical characteristics between experimental and software was analyzed using $\mathrm{T}$-test, $\mathrm{P}=95 \%$. The physical stability and in vitro SPF of the optimum formula were observed. The study exhibits that the combination of cetyl alcohol $9.71 \%$, mineral oil $29 \%$, and tween $803.29 \%$ was the optimum formula of o/w cream with the desirability test 0.924 . The T-test result shows that there is no significant differences $(p>0.05)$ on physical characteristics between experimental and software prediction. During the storage, the viscosity, spread ability, adhesive ability, separation volume ratio of cream were relatively stable. However the stability started to decline on the week IV in the extreme temperature. The SPF of the cream of the CFR, CPHR and CBZP partition were $21.32 ; 33.12$ and 42.49 , respectively.
\end{abstract}

Key words: Mahkota dewa, cream, optimum, SPF

\section{INTRODUCTION}

Ultraviolet (UV) radiation of sunlight causes skin damage on the human skin, sunburn, brown spot, thickening of epidermis and dry skin (Moyal, 2012). UV B has wavelengths ranging $290-320 \mathrm{~nm}$, this radiation stimulates the tanning of skin. Tanning appears in 2-3 days after sunburn and will disappear in a month. Meanwhile, UV A has greater effect of pigmentation than UV B ( Moyal, 2012; Poskitt et al., 1979). UV filter is the compound of sunscreen which is able to interact with UV radioation through 3 basic mechanisms (reflection, absorption or scattering of UV light) (Moyal and Fourtanier, 2004; Cumpelik, 1972). The active compound which be able to absorb, scatter or reflect the energy of sunlight that reach the human skin, named sunscreen (Pathak and Fitzpatric, 1993).
Food Drug Administration (USA) presupposes the marketed sunscreen should have minimum SPF 2 (Draelos and Thaman, 2006). One of approved compounds for used in the manufacture formulation is derivative of benzophenone. Benzophenon and its derivatives show excellent photostability and act as sunscreen (Finnen, 2005). Mahkota Dewa (Phaleria macrocarpa (Scheff) Boerl) is commonly used traditionally as herbs, both as single use and as mixture with other traditional medicines (Dalimarta, 2003). Mahkota Dewa contains phenolic compounds which in great ammount is found in leaf as benzophenone glycoside or Phalerin (Wahyuningsih et al., 2005). Shovyana and Zulkarnain (2013), had studied physical stability assessment of topical and sunscreen activity of $\mathrm{o} / \mathrm{w}$ cream of ethanolic extract of mahkota dewa fruit subjected to mice. 
Table I. Composition and concentration of the optimum formula of o/w cream

\begin{tabular}{|c|c|c|c|c|c|c|c|c|c|c|c|c|c|}
\hline \multirow{2}{*}{ Ingridient } & F-A & F-B & F-C & F-D & F-E & F-F & F-G & F-H & F-I & F-J & F-K & F-L & F-M \\
\hline & $(\%)$ & $(\%)$ & $(\%)$ & $(\%)$ & $(\%)$ & $(\%)$ & $(\%)$ & $(\%)$ & $(\%)$ & $(\%)$ & $(\%)$ & $(\%)$ & $(\%)$ \\
\hline Mahkota dewa & 6 & 6 & 6 & 6 & 6 & 6 & 6 & 6 & 6 & 6 & 6 & 6 & 6 \\
\hline Cetyl Alcohol & 7.67 & 7.67 & 7.67 & 7.67 & 3 & 3 & 10 & 10 & 5.33 & 5.33 & 10 & 10 & 10 \\
\hline Mineral Oil & 26.67 & 29 & 26.67 & 24.33 & 29 & 29 & 22 & 29 & 29 & 26.67 & 22 & 24.33 & 26.67 \\
\hline & 7.67 & 5.33 & 7.67 & 10 & 10 & 10 & 10 & 3 & 7.67 & 10 & 10 & 7.67 & 5.33 \\
\hline & 10 & 10 & 10 & 10 & 10 & 10 & 10 & 10 & 10 & 10 & 10 & 10 & 10 \\
\hline & 1.15 & 1.15 & 1.15 & 1.15 & 1.15 & 1.15 & 1.15 & 1.15 & 1.15 & 1.15 & 1.15 & 1.15 & 1.15 \\
\hline Methyl paraben & 0.2 & 0.2 & 0.2 & 0.2 & 0.2 & 0.2 & 0.2 & 0.2 & 0.2 & 0.2 & 0.2 & 0.2 & 0.2 \\
\hline Prophyl paraben & 0.1 & 0.1 & 0.1 & 0.1 & 0.1 & 0.1 & 0.1 & 0.1 & 0.1 & 0.1 & 0.1 & 0.1 & 0.1 \\
\hline Aqua ad & 100 & 100 & 100 & 100 & 100 & 100 & 100 & 100 & 100 & 100 & 100 & 100 & 100 \\
\hline
\end{tabular}

Note: Formula C, F, and $\mathrm{K}$ were used to validate SLD equation

In this study we used P.macrocarpa leaves because the leaves can produce continuously regardless of the season as well as fruit. Sunscreen is a cosmetic which is commonly applicated to skin epidermis. It usually consists of active ingredient that act as photoprotector. It absorbs or scatter sunlight so the amount of radiation which reach the skin can be reduced. Benzophenone and oxybenzophenone are used widely for cosmetic (Wasitaatmadja, 1997; Perwitasari et al., 1999). Phenolic compound is natural photo protector that found in plant. This compound has activity to protect the damage of plant tissue due to sunlight exposure (Halliwel and Gutteridge, 1999; Wilkinson and Moore, 1982). The formulations used were $\mathrm{o} / \mathrm{w}$ cream containing the active partition (CFR) compared to control phalerin (CPHR) and positive control benzophenone (CBZP). Phalerin (CPHR) was used as a control because in the active partition (CFR) containing phalerin $18.26 \%$ and it has benzophenon frame work, while CBZP used as positive control because these substances were commonly used as sunscreen that avaible in market. Based on the existence of active compound of mahkota dewa leaves, the study was aimed to evaluate the physical stability of optimum formula of $\mathrm{o} / \mathrm{w}$ cream. The designed formula contains substance from mahkota dewa leaves which show in vitro SPF activity. SPF value is used to evaluate the effectivity of sunscreen (Schalka and Reis, 2011).

\section{MATERIAL AND METHODS Materials}

Mahkota dewa leaves were collected in Kulonprogo. Ethanol 70\%, petroleum ether, cetyl alcohol, mineral oil, Tween 80 , glycerine, span 80, methyl paraben, prophyl paraben, Benzophenone, aquadest (pharmaceutical grade), Ethyl acetate, Chloroform, Methanol (pro analysis) were prepared.

\section{Equipments}

ULTRA-TURRAX T25 (JANKE \& KUNKEL IKA®-Labortechnik), viscotester VT 04 (Rion Co. Ltd, Japan), spectrophotometer (Hitachi, UV-3200, Japan), pH meter, refrigerator, Vortex.

\section{Preparation of compound by partition of mahkota dewa leaf}

Powder of mahkota dewa leaves $(2 \mathrm{~kg}$ ) were macerated in ethanol for 3 days. The ethanolic extract was separated by filtration using Buchner funnel and the extract was dried in vacuum evaporator. Then, the extract was triturated by petroleum eter and centrifuged to give the insoluble fraction, which containing phalerin

\section{Optimation of formula}

The optimation $\mathrm{o} / \mathrm{w}$ cream formula consists $6 \%$ of insolube partition of mahkota dewa leaves was carried out using (SLD) Simplex Lattice Design method (Table I). The main composition of the optimation of formula 
was cetyl alcohol, mineral oil and tween 80 as independent variables.

\section{Preparation of $0 / w$ cream}

The oil phase was heated at $65-75^{\circ} \mathrm{C}$ in waterbath. At the same time, separateley, the aquous phase was heated in the same conditon. The oil phase was poured into beaker glass while stirring using dispersion ULTRA-TURRAX T25. The aqueous phase was added to the oil phase drop by drop while keep stirring constantly. The cream was cooled down while keep being stired. Finally, the active compound of mahkota dewa leaves was added and stirred until homogeneous of cream was obtained.

\section{Physic sta bility test}

Measurement stability test was observed for 4 weeks on the regular storage. The test were Viscosity Test, Adhesive Ability Test, Spreadability Test, $\mathrm{pH}$ Determination, Stability Test using Freeze Thaw Cycling Method, and dermination of in vitro SPF of sunscreen cream were measured using Spectrophotometer.

\section{Viscosity test}

The sample was put in a chamber, then install rotor no.1 where the rotor was dipped into sample. The viscosity tester was turned on and the stable of dart or equipment showed the viscosity value on $\mathrm{dPa}$.S. unit.

\section{Adhesive ability test}

Approximately $0.1 \mathrm{~g}$ of sample was lubricated on glass object (in certain area: $2 \mathrm{x}$ $2 \mathrm{~cm}$ ), covered with other glass and pressed with $1 \mathrm{~kg}$ load for $5 \mathrm{~min}$. The object glass was installed in the equipment, load to $80 \mathrm{~g}$ was pulled out and record the duration when the both sides of glass separated.

\section{Spread ability test}

Approximately $0.5 \mathrm{~g}$ of sample was put in the centre of scale spherical glass, covered with other glass. Then it is waited for a minute then record the area of spread for 48 sides. In every step, the glass was loaded with $50 \mathrm{~g}$ and again wait for a minute. The step was done until loaded 300g.

\section{pH determination}

Twenty gram of sample was put into a beaker glass and measured with a calibrated $\mathrm{pH}$ meter (calibration at $\mathrm{pH} 4$ and 7). The stable value on the $\mathrm{pH}$ meter was reckoned.

\section{Stability test using Freeze Thaw Cycling method}

The sample was put in scale test tube until definite value, and the tube was stored at room temperature. The separation volume of the cream was observed in alternate day until the $30^{\text {th }}$ day. If during investigation, there was no any separation the test should be accelerated. The test was done by putting the tube under stress condition at $45^{\circ} \mathrm{C}$ and $8^{\circ} \mathrm{C}$ alternately for 3 cycles ( 1 cycle $=24$ hours $)$ The separation volume ratio can be calculated using this equation below:

$F=\frac{H t}{H o}=\frac{V t}{V o}=\frac{L \times H t}{L \times H o}$

\section{Where:}

$$
\begin{array}{ll}
\mathrm{F} & : \text { Separation Volume Ratio } \\
\mathrm{Ht} & : \text { Height of emulsion }(\mathrm{t}) \\
\mathrm{Ho} & : \text { Height of emulsion }\left(\mathrm{t}_{0}\right) \\
\mathrm{Vt} & : \text { Volume of emulsion }(\mathrm{t}) \\
\mathrm{Vo} & : \text { Volume of emulsion }\left(\mathrm{t}_{0}\right) \\
\mathrm{L} & \text { : Surface Area (Mollet and } \\
& \text { Grubenmann, 2001). }
\end{array}
$$

\section{Determination of in vitro SPF of cream}

Five hundred $\mathrm{mg}$ of cream was weighed and put in a flask $(50 \mathrm{~mL})$ and added methanol then dispersed using Vortex for 5 minutes. The obtained dispersion was filtered using filter paper. The filtered solution $5 \mathrm{~mL}$ of was adjusted to $50 \mathrm{~mL}$ using methanol. The absorbance of each sample was determined by spectrophotometry in the range of $290-320 \mathrm{~nm}$ (UVB) with $5 \mathrm{~nm}$ intervals. The SPF of each sample was determined with the data obtained by spectrophotometric analysis, using the equation:

$$
S P F=C F \sum_{290}^{320} E E(x) I(x) A B S(x)
$$

Where:

$$
\begin{aligned}
\mathrm{SPF} & =\text { sun protecting factor, } \\
\mathrm{CF} & =\text { Correction Factor }=10 \\
\mathrm{EE}(I) & =\text { Erythema effect spectrum } \\
\mathrm{I}(I) & =\text { solar intensity spectrum } \\
\mathrm{ABS}(\chi) & =\text { absorbancy or sample Value of EE.I } \\
& \text { is constant=1 (Mansur, et al., 1986). }
\end{aligned}
$$


Tabel II. The result of T-test between prediction physical characteristic and experimental physical characteristic of $\mathrm{o} / \mathrm{w}$ cream

\begin{tabular}{lcccc}
\hline Response & Prediction & Trial & Significance & Conclusion \\
\hline Viscosity & 115.67 & 113.33 & 0.342 & No Significant Difference \\
Adhesive Ability & 3.83 & 3.967 & 0.089 & No Significant Difference \\
Spread Ability & 0.704 & 0.74 & 0.071 & No Significant Difference \\
\hline
\end{tabular}

Table III. The viscosity, spread ability and adhesive ability of optimum o/w cream mahkota dewa

\begin{tabular}{crcc}
\hline Week & Viscosity (dPa.s) & Spread Ability (cm) & Adhesive Test (s) \\
\hline $\mathbf{0}$ & $113.33 \pm 6.638$ & $3.967 \pm 0.252$ & $0.740 \pm 0.02$ \\
$\mathbf{1}$ & $112.67 \pm 6.667$ & $3.967 \pm 0.252$ & $0.730 \pm 0.02$ \\
$\mathbf{2}$ & $107.67 \pm 3.215$ & $3.700 \pm 0.100$ & $0.723 \pm 0.015$ \\
$\mathbf{3}$ & $106.67 \pm 4.163$ & $3.617 \pm 0.104$ & $0.707 \pm 0.015$ \\
$\mathbf{4}$ & $101.0 \pm 1.606$ & $3.700 \pm 0.100$ & $0.673 \pm 0.021$ \\
\hline
\end{tabular}

Table IV. SPF o/w cream on the CFR, CPHR and CBZP

\begin{tabular}{cccccc}
\hline No & $\boldsymbol{\chi}$ & EE.I & CFR (EE.I.A) & CPHR (EE.I.A) & CBZP (EE.I.A) \\
\hline 1 & 290 & 0.0150 & 0.0369 & 0.0614 & 0.0634 \\
2 & 295 & 0.0817 & 0.1938 & 0.3299 & 0.3805 \\
3 & 300 & 0.2874 & 0.6193 & 1.0631 & 1.1770 \\
4 & 305 & 0.3278 & 0.6962 & 1.1143 & 1.4438 \\
5 & 310 & 0.1864 & 0.3817 & 0.5233 & 0.7679 \\
6 & 315 & 0.0837 & 0.1683 & 0.1875 & 0.3386 \\
7 & $320 \boldsymbol{\chi}$ & 0.0180 & 0.0358 & 0.0326 & 0.0811 \\
\hline \multicolumn{7}{r}{} & SPF & $\mathbf{2 1 . 3 2}$ & $\mathbf{3 3 . 1 2}$ & $\mathbf{4 2 . 4 9}$ \\
\hline
\end{tabular}

Where: $\mathrm{CFR}=$ Formula with partition extract of mahkota dewa $6 \%$; CPHR $=$ Formula with phalerin $6 \%$; $\mathrm{CBZP}=$ Formula with benzofenon $6 \%$.

\section{RESULTS AND DISCUTION}

The active partition of $P$. macrocarpa leaves contain phalerin with $19.0 \%$ rendement was brown, smelt distinctive odor, and tasted bitter.

\section{Determination of optimum formula of $0 / w$ cream}

The optimization of formula o/w cream mahkota dewa was performed by varying the concentration of the ingredients. Formulation was done in a range position (goal) so the formula determination (suggested by Design Expert $\mathbb{R}$ versi 9.01) would be in the expected range, at the $0-100$ value.

The evaluation of physical viscosity characteristic was performed in "is maximize" meanwhile adhesive ability was in "is target" so the expecting formula would provide targeted value. At same time, the evaluation of physical adhesive ability was done in "is in range" so the determination formula gave value which included in the expecting range minimum and maximum. The result of physical characteristic test can be seen in this table II to set the equation of Simplex Lattice Design o/w Cream

The optimum formula was obtained

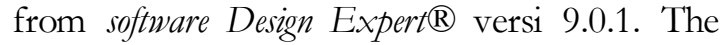
analysis presented the superimposed from contour plot viscosity response, spread ability, and adhesive ability of $\mathrm{o} / \mathrm{w}$ cream. Based on the prediction of the software, it was selected one formula with the highest desirability value, 0.924 (Figure 1). The optimum formula of o/w cream based on the software consisted of cetyl alcohol $9.71 \%$, mineral oil $29 \%$, and Tween 80 $3.29 \%$ (Figure 2).

The prediction response was $115.67 \mathrm{dPa} . \mathrm{s}$, adhesive ability time was $0.704 \mathrm{~s}$, and spread diameter was $3.83 \mathrm{~cm}$. Figure 2 shows the Overlay plot Response in the optimum formula. 


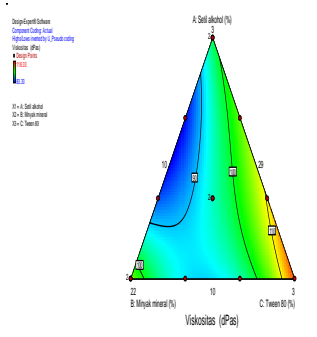

a)

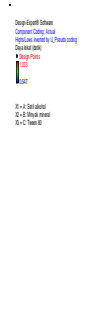

b)

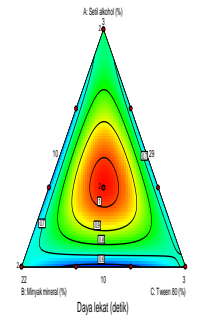

c)

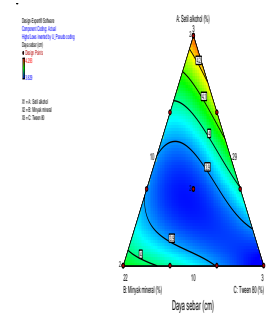

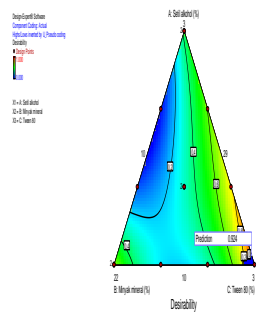

d)

Figure 1. Countourplot a) Viscosity, b) Spread Ability, c) Adhesive Ability d). Superimposed $\mathrm{O} / \mathrm{w}$ cream
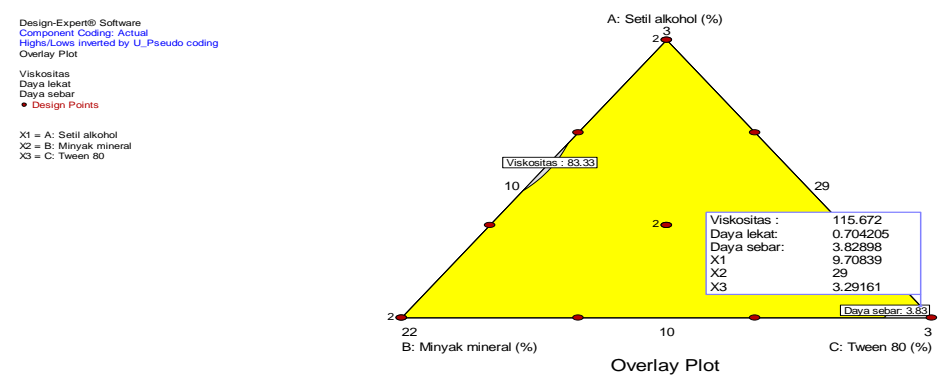

Figure 2. Overlay plot Response in the optimum formula on viscosity test, spread ability, adhesive ability Mahkota Dewa o/w cream

The data were used to establish optimum formula was baseline 0 week because at this time the cream were still stable. T-test was performed to analyze the average difference betw een real data with hypothesis value. The Ttest result between prediction formula with experimental formula was exhibited in the Table II. The statistic analysis showed there was no significant difference between physical characteristic prediction with experimental physical characteristic of o/w cream. Therefore the experimental response was in accordance the prediction of software Design Expert $\mathbb{R}$ versi 9.0.1. (significancy $>0.05$ ). The composition of optimum formula of $\mathrm{o} / \mathrm{w}$ cream based on software Design Expert ${ }^{\circledR}$ version 9.0.1: Cetyl alcohol $9.71 \%$, mineral oil $29 \%$; and tween 80 $3.29 \%$.

Physic stability test of the selected formula of mahkota dewa $\mathrm{o} / \mathrm{w}$ cream was performed during storage time for 4 weeks. No physical change was observed in any of the sample stored up to $4^{\text {th }}$ week. The monitoring was included change of organoleptic (color, smell, and feel) and properties (homogenety and $\mathrm{pH}$ ). The findings revealed that the freshly prepared and during storage period, cream were turn brown with distinctive odor. The color changes were due to active compound mahkota dewa leaves. The formulation showed that the cream had homogeneously soft texture.

Cream formulated in this work had a pH value range of 5.53-5.70, which is close to the neutral $\mathrm{pH}$. Moreover, the various $\mathrm{pH}$ of the cream samples stored were noted to undergo a continuous decrease up to one month of observation (Figure 3). Indicating the stability was influenced by storage duration $(\mathrm{p}<0.05)$. Moreover, there was no any difference $\mathrm{pH}$ of the formulation during monitoring on within 2 weeks ( $\mathrm{t}$ test $=0.074, \mathrm{p}>0.05$ ). However the $\mathrm{pH}$ values of the formulation did not affect the overall quality of cream because the $\mathrm{pH}$ values remained at $\mathrm{pH}$ 4.5-6.5. 


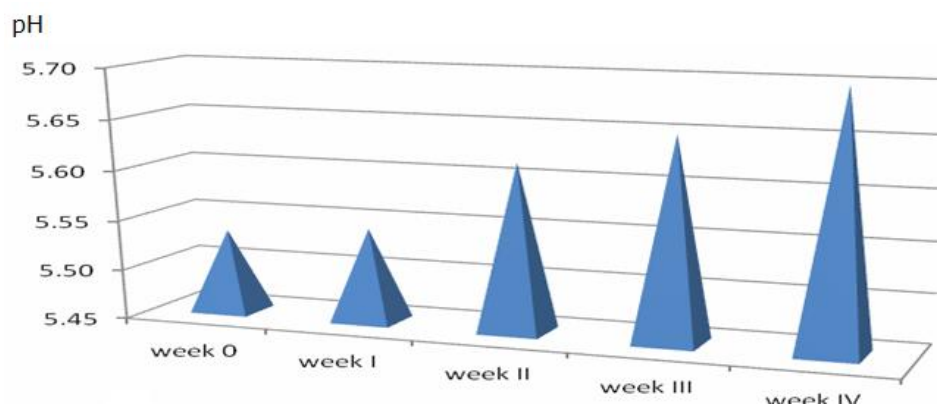

Figure 3. The change of $\mathrm{pH}$ value during one month of observation

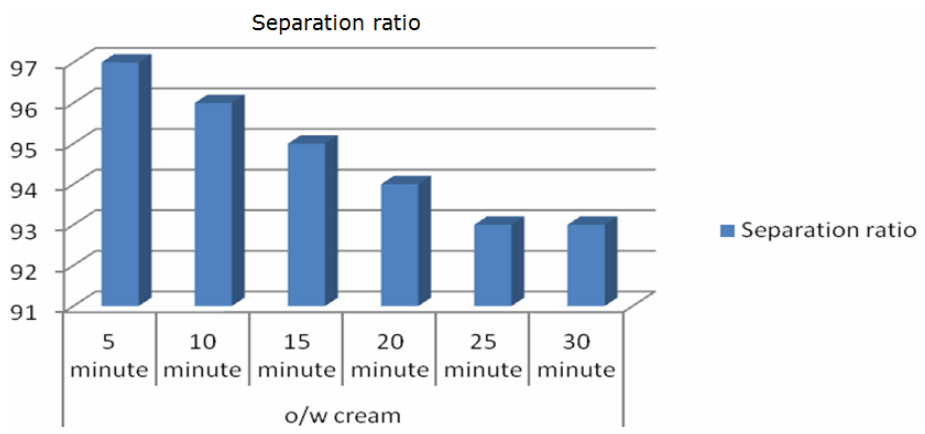

Figure 4: Centrifugation report at speed of $4500 \mathrm{rpm}$

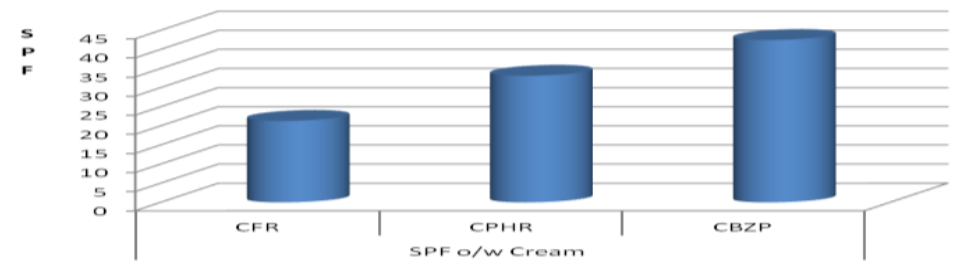

Figure 5. Histogram of SPF evaluation using spectrophotometer

Where: $\mathrm{CFR}=$ cream with partition compound; $\mathrm{CPHR}=$ cream with phalerin; $\mathrm{CBZP}=$ cream with benzophenone

As far as the findings of the present study, the decrease of viscosity was reported for the cream in any of the storage conditions (Table III). The decrease of viscosity of the selected formulation may be influenced by dehydration of the cream during storage time. The dehydration leads to be britlle cream and could not resistant to rotor stirring of the instrument. The cream resistant was declined to flow. The decreasing of viscosity might be due to depolymerization of emulsifier in cream formula (Owen, 2005; Bonner, 2009). How ever, statistical test indicated no significant difference between viscosity at $1^{\text {st }} 4^{\text {th }}$ week (significancy>0.05).
Spreadability of the mahkota dewa o/w cream formulation was tended to increase during storage period. This fact was comparable with the decrease of crean viscosity so that the spreadability response was greater. The spreadability remained stable up to $1^{\text {st }}$ week. The decrease started from $2^{\text {nd }}$ week until the end of observation. The change of spreadability may be contributed by the change of temperature. The observation was done at the range temperature of $20-30^{\circ} \mathrm{C}$. The increase of temperature storage leads to viscosity increase and to decrease of the spreadability. Statistic analysis of paired test $(\mathrm{P}=95 \%)$ indicated no significance difference of spreadability to the end of storage (Table IV). 
The observation presented the stable adhesive ability of formulated cream up to week $2^{\text {nd }}$ although it started to decrease at week $3^{\text {rd. }}$ This result was similar with the evaluation of spreadability. The insignificant response among observation can be related to the change of adhesive ability. The change of temperature storage will affect the viscosity of the samples. The decrease of viscosity will lead to the greater spread ability and the smaller adhesive ability at the same time. The paired $t$-test analysis showed there was significant difference of the adhesive ability during storage period (significancy $<0.05$ ), except between week $1^{\text {st }}$ and $2^{\text {nd }}$ week.

The study aimed to describe the stability of the cream on long-term storage. To shorten the observation period, the test was done by performing accelerated stability test. The test was performed to evaluate the viscosity of the cream and monitor the color change. The observation at the room temperature storage for all the formula (started $1^{\text {st- }} 4^{\text {th }}$ week) did not show any separation, so it can be mentioned that the formulation was stable. The accelerated test was performed by keeping the formula at temperature $45^{\circ} \mathrm{C}$ and $8^{\circ} \mathrm{C}$ alternately (freeze thaw cycling). One cycle of test consisted of $24 \mathrm{~h}$ storage at $45^{\circ} \mathrm{C}$ and $24 \mathrm{~h}$ storage at $8^{\circ} \mathrm{C}$. The observation founded that there was no color change in the surface of formulation. How ever, there was an increase of viscosity of the formulation at $4^{\text {th }}$ week. The cream was not cracked and remained stable during observation (Mollet and Grubenmann, 2001). It can be concluded that all various formulation of cream were stable. The paired $t$ test resulted that there was a significant difference with significant value $(\mathrm{p}<0.05)$. The results of 4 weeks storage under extreme condition of the selected cream showed the sign of separation. The cream separated due to the fact that higher temperature will increase the kinetic energy of particle drops so making easier for the same phase to coalesce. The rising temperature leads to the decrease of viscosity. According to the Stokes law, the decrease of viscosity causes the dispersed particles of the cream affiliate and form bigger particle and conduct the separation. Freezing can damage emulsion because it can damage the spherical shape of the emulsion drops (Lachman, et al., 1994). Accelerated stability test can be performed in the stress condition e.g. temperature and mechanic factor. One of the mechanic separation test is by centrifugation (Lachman et al., 1994) (Figure 4).

Separation phase was observed after centrifugation $(4500 \mathrm{rpm})$ in any of the samples stored. It was known that the longer centrifugation time will lead to the greater ratio of separation volume. This phenomena was caused by high speed of centrifugation will change the dispersed intern phase and trigger the coalescence of cream. Briefly it can be said that the greater high speed of centrifugation will lead to the faster of the separation of the cream.

Evaluation of the SPF was performed by in vitro experiment using UV spectrophotometer. Based on determination of SPF using Mansur method (1986), it was known that mahkota dewa cream displayed potential activity as sunscreen (Table IV). The SPF value of $\mathrm{o} / \mathrm{w}$ cream was 21.32. The activity of mahkota dewa as sunscreen was supposed to be the presence of a benzophenone glycoside $(4,5-$ dyhydroxy,4'-metoxybensophenone-3-O- $\beta$-Dglycoside) that was able to absorb UV light at $294 \mathrm{~nm}$ and phalerin absorbs UV light at 292 nm (Wahyuningsih et al., 2005; Tambunan \& Simanjuntak, 2006) (Table VI). The Phalerin compound also displayed activity as antioxidants. Antioxidants counteract to free radicals from UV rays that damage the skin. The Phalerin reduced DPPH absorbance (Wijanarko et al., 2006). Other study using Phalerin compound, showed that Phalerin could induce macrophage phagocytic activity significantly $(p<0.05)$ (Wijanarko et al., 2005). This study described that formula $\mathrm{O} / \mathrm{w}$ cream containing CFR, CPHR and CBZP had SPF 21.32; 33.12 dan 42.49, respectively (Figure 5). The research using cream of ethanolic extract mahkota dewa leaves as a sunscreen in-vivo, showed that cream at concentration 4, 6, 8 and $10 \%$ have an activity as a sunscreen with an SPF value of $1.25 ; 1.56 ; 2.4$; and 3.05 . In addition the mahkota dewa have a good physical stability during storage (Shovyana et al., 2013). The extract of mahkota dewa fruit has low sunscreen activity, but the other research 
about SPF in vitro of mahkota dewa extract and partition product with concentration of $6 \%$ on $\mathrm{o} / \mathrm{w}$ cream, produced SPF values higher than the extract. The results for the extract was 9.60 and for the partition was 21,32 (Zulkarnain et al., 2015). Other studies with different methods from curcuma mango (Yuliani, 2010) about the optimization of the combination of sorbitol, glycerol and polyethyleneglycol in sunscreen gel ethanol extract of curcuma mango, it also had an SPF value. The method was used the direct determination of fluid extract of curcuma mango with volume of $1 \mathrm{ml}, 1.25 \mathrm{ml}, 1.50 \mathrm{ml}$ and $1.75 \mathrm{~mL}$, then the SPF values obtained in vitro was 9.94; 15.18; 21.88 and 27.98, respectively. The other study about the sunscreen activity of herbal formulation (Mishra et al., 2012). The in vitro SPF by spectrophotometry method of Calendula flower oil in a cream formulation had The SPF 14.84 \pm 0.16 .

\section{CONCLUSION}

This study presented that optimum formula of $\mathrm{o} / \mathrm{w}$ cream based on software were variation of cetyl alcohol $9.71 \%$, mineral oil $29 \%$, and tween $803.29 \%$, with desirability value at 0.924 .

The $\mathrm{o} / \mathrm{w}$ cream contained partition compound (CFR), Phalerin (CPHR) and benzophenone (CBZP) had SPF value 21.32; 33.12 dan 42.49 respectively.

\section{ACKNOWLEDGEMENT}

The Authors are grateful to the Faculty Pharmacy of UGM Yogyakarta for the grants from IMHERE sub-activity 3.1-III (Enhancing International Collaboration in Pharmaceutical Education and Research) project and for supporting the research at the Faculty of Pharmacy, Mahidol University Thailand.

\section{REFE RE NCES}

Bonner MC., 2009, glycerine, in Rowe, R.C., Sheskey, P.J., and Quinn, M.E., Handbook of Pharmaceutical Excipients, $6^{\text {th }}$ Ed, 380, Pharmaceutical Press, London. Cumpelik BM., 1972, Analytical Prosedures and Evaluation of Sunscreen, J.Soc. Cos. Chem., 23: 333-345.
Dalimartha S. 2003, Atlas of Medicinal Plants Indonesia, Poster Agriwidya, Jakarta, Volume III, 62-65.

Draelos ZD., Thaman LA., 2006, 157-159, Cosmetic Formulation of Skin Care Products, Taylor and Francis Group, New York

Finnen MJ., cit Rahmi, Iqmal. 2005, in Silico Analysis Activity Sunscreen Compound derivatives oxybenzone Using semiempirical Molecular Orbital Calculation Zindo / s, Indonesian Pharmacentical Journal, vol. 2 No. 1: 88-92.

Halliwell B. and Gutteridge JMC., 1999, Free Radical Biology and Medicine, Oxford University Press, New York, 204,301.

Lachman L., Lieberman HA. and Karrig JL., 1994, Theory and Practice of Industrial Pharmacy, translated by Siti Suyatmi, Publishers Press, University of Indonesia, Jakarta, Volume 2, Issue III: 1081.

Mishra AK., Mishra AA. And Chattopadhyay P., 2012, Assessment of In vitro Sun Protection Factor of Calendula Officinalis L. (Asteraceae) Essential Oil Formulation, J Young Pharm., JanuaryMarch; 4(1): 17-21.

Mansur JS., Breder MN., Mansur MC., Azulay RD., 2012, Determination of Sun protecting factor by spectrophotometry, An Bras Dermatol, 61: 121-4 cit. AK Mishra, Mishra A, P. Chattopadhyay, Assessment of in vitro Sun Protection Factor of Calendula Officinalis L. (Asteraceae) Essential Oil Formulation, Young J Pharm Jan-Mar., 4 (1): 17-21.

Moyal D., 2012, Need for a well-balanced sunscreen to protect human skin from both Ultraviolet A and Ultraviolet B damage., Indian J Dermatol Venereol Leprol; 78, Suppl: S2430.

Moyal D., Fourtanier A., 2004, Acute and chronic effects of UV on skin: Rigel DS., Weiss RA., Lim HW., Dover JS., editors. Photoaging. New York: Mercel Dekker, Inc, $\mathrm{p}$ 15-32.

Mollet H. and Grubenmann A., 2001, Formulation Tecbnology : Emulsions, Suspensions, Solid Form, 261-262, WileyVch, Toronto. 
Owen SC., 2005. Mineral Oil, dalam Rowe, R.C., Sheskey, P.J., and Owen, S.C., Handbook of Pharmaceutical Excipient, Fifth Edition, 471-473, Pharmacentical Press, London.

Poskitt EM., Cole TJ. and Lawson DE., 1979, the Diet, Sunlight, and 25-hydroxyvitamin $\mathrm{D}$ in Healthy Children and Adults. Brit Med, 1: 221.

Pathak MA., Fitzpatric TB., 1993, Preventive Treatment of Sunburn, Dermatochiosis, and Skin Cancer with Suprotective Agent, dalam Fitzpatrick TB., Eisen AZ., Walff K., Freedberg IM., Aisten KF.(Eds), Dermatology in General Medicine, 16891715, 4th Ed., McGraw Hill, New York.

Perwitasari I., Chandra DK., Etnawati, Suyoto, 1999., the role of Sunscreen Combinations cinnamic and Benzophenon on Skin Color Changes Constitutive result of exposure to UV-B, set Cosmetic Medical Journal, FKU-UGM, Yogyakarta, 16-20.

Shovyana HH. and Zulkarnain AK., 2013, Physical Stability and Activity of Cream W / O Ethanolic Fruit Extract of Mahkota Dewa (Phaleria macrocarpa (Scheff.) Boer.) As a Sunscreen, MOT, Vol 18 No. 2 May-August 2013, p. 109117.

Schalka S. and Reis VM., 2011, Sun protection factor: meaning and Controversies, $A n$ Bras Dermatol., 86 (3), 507-15.

Tambunan RM., Simanjuntak P., 2006, The Chemical Structure Determination of Antioxidant Benzophenone glycosides of n-Butanol Leaf Extract Mahkota Dewa (Phaleria macrocarpa (Scheff.) Boerl.), Indonesian J. Pharm, Vol. 17 (4) : 184-189.
Wahyuningsih MS., Mubarika S., Gandjar IG., Hamann MT., Rao KV., Wahyuono S., 2005, Phalerin, New Benzophenon glucoside isolated from methanolic fraction Mahkota Dewa (Phaleria macrocarpa (Scheff) Boerl.), Indonesian J. Pharm, 16 (1), 51-57.

Wasitaatmadja BC., 1997, Guidance Cosmetic Medical Sciences, University of Indonesia Press, Jakarta: 105-108.

Wijonarko H., Wahyuningsih MSH., Mubarika S., Ganjar IG., Wahyuono S., 2006, Antiradical activity of Phalerin isolated from the leaves of Mahkota Dewa ( $P$. macrocarpa (Scheff). Boerl), J TradMedicine, 11(35).16-20.

Wijanarko H., Wahyuningsih MSH., Mubarika S., Ganjar, IG., Wahyuono S., 2005, Activity of Phalerin Isolated from the Leaves of Mahkota Dewa (Phaleria macrocarpa (Scheff). Boerl) as Macrophage Phagocytic Induction in Vitro. J Traditional Medicine, 10(33) 11-15

Wilkinson, J.B. and Moore, R.J., 1982, Harry's Cosmeticology, $7^{\text {th }} \mathrm{Ed}$., George Godwin, London.

Yuliani SH., 2010, The optimization of the combination of sorbitol, glycerol and polyethyleneglycol in sunscreen gel ethanol extract of Curcuma mango, Indonesian J. Pharm., Vol. 21 No. 2 (2010), 83-89.

Zulkarnain AK., Marchaban, Wahyuono S. and Susidarti RA., 2015, Effect Lotion-cream Phaleria macrocarpa Concentration on Stability and Sunscreen Activity by Spectrophotometry, Jo Pharmaceutics, Vol. 11 No. 3 (2015). Inpress. 